\title{
Empirical Studies of Patterning
}

\author{
Robert Pasnak \\ George Mason University, Fairfax, VA, USA \\ Email: rpasnak@gmu.edu
}

How to cite this paper: Pasnak, R. (2017) Empirical Studies of Patterning. Psychology, 8, 2276-2293.

https://doi.org/10.4236/psych.2017.813144

Received: August 26, 2017

Accepted: November 27, 2017

Published: November 30, 2017

Copyright (C 2017 by author and Scientific Research Publishing Inc. This work is licensed under the Creative Commons Attribution International License (CC BY 4.0).

http://creativecommons.org/licenses/by/4.0/

\begin{abstract}
Young children have been taught simple sequences of alternating shapes and colors, referred to as "patterning", for the past half century in the hope that their understanding of prealgebra and their mathematics achievement would be improved. The evidence that such patterning instruction actually improves children's academic achievement is scanty. However, recent research shows that instruction on more complex patterns produces advances in both mathematics and reading achievement. Patterning instruction should change accordingly. Further research is needed to assess the cognitive mechanisms involved, which children benefit from such instruction, and the patterns that will produce the greatest gains.
\end{abstract}

\section{Keywords}

Patterning, Sequences, Mathematics, Reading, Literacy, Prealgebra

\section{Introduction}

Nearly all psychologists younger than 70 who went to elementary school in English-speaking and some other countries were taught "patterning" in kindergarten, and often in preschools or first grade, as a form of cognitive intervention. Yet no psychologists, other than the author and his students, have studied patterning. It has been exclusively a province of educators. This paper is an attempt to bring patterning to the attention of psychologists who study cognitive development, in hopes of spurring research into this aspect of cognitive development.

"Patterning" is the ability to abstract the rule that defines a predictable sequence of items appears to be an important step in the development of young children's thinking. Certainly millions of children have received instruction on this form of abstraction during the past half century. Abstracting sequences of items, or "patterns" is also a feature of some intelligence tests. Yet until recently there has been very little empirical research on this aspect of cognitive develop- 
ment. Its incorporation into curricula has been based on reasoned argumentation and consensus by educators. However, empirical research has burgeoned in the past few years. Moreover, empirical research on the cognitive mechanisms that underpin children's ability to abstract simple alternating patterns and more complex patterns has begun.

The present paper constitutes a review of all of the experimental research on patterning by young children. It begins with descriptions of longitudinal studies of the relations between alternating patterns and academic achievement, proceeds to studies of the effects of instruction on alternating patterns, and then to longitudinal studies of complex patterns and the effects of instruction with complex patterns. Then, what is known about the effects of pattern characteristics, the development of patterning in young children, and cognitive mechanisms that may be involved in patterning, according to empirical studies, is reviewed. The paper ends with recommendations for changes in instruction that take advantage of recent findings, and offers suggestions for research on this feature of early elementary school instruction.

\subsection{Alternating Patterns}

Instruction on alternating patterns has been endorsed by national organizations (National Council of Teachers of Mathematics, 2015), and the joint position statement of the National Association for the Education of Young Children/National Council of Teachers of Mathematics Education (2002/2010). It is part of preschool curricula, e.g., Building Blocks (Sarama \& Clements, 2004) and PASMAP (Mulligan, Mitchelmore, Kemp, Marston, \& Highfield, 2008). Economopolous' (1998: 230) statement that "If you ask any kindergarten teacher, she or he is likely to consider the study of patterns an essential part of the mathematics program" is apt.

Alternating patterns are those wherein items alternate in color, size, or shape. Examples of such patterns would be simple alternations such as oval, rectangle, oval, rectangle, oval, rectangle. Children would be asked what shape should come next, and often are asked to extend the sequence, or duplicate it with different materials. Frequently they are taught double alternations (e.g. red, red, $\tan$, tan, red, red, tan, tan,) or alternations of intermediate complexity (e.g., large, large, small, large, large, small, or pink, blue, blue, pink, blue, blue). Sometimes such patterns have three elements (disc, triangle, square, disc, triangle, square). This instruction is termed "patterning". Lessons on patterning are thought to improve children's cognitive development and improve academic achievement, and manuals on how to teach patterning have been plentiful (e.g., Burton, 1982; Jarboe \& Sadler, 2003).

\subsubsection{Longitudinal Studies of Alternating Patterns}

Two studies involving the same sample of preschoolers from low income homes have emerged recently that show longitudinal relations between understanding alternating patterns and later mathematics achievement. Rittle-Johnson, Hofer, 
Fyfe, and Farren (2015) found significant regression coefficients ranging from 0.08 to 0.17 between children's understanding of patterning at age 7 and KEYmath measures of prealgebra, numeration, geometry, and a composite mathematics measure at age 11. The patterning measure was derived from the Research-based Early Math Achievement measure devised by Clements, Sarama, and Liu (2008). There were no significant relations between the patterning scores and either the Woodcock-Johnson (W-J) mathematics concepts scale 18 or a state achievement test. In contrast, Fyfe, Rittle-Johnson, Hofer, and Farren (2015) found significant regression coefficients of 0.18 and 0.17 between the preschoolers' understanding of alternating patterns and their fifth grade scores on geometry and a composite measure of mathematics-W-J scales 10 and 18 . The coefficients diminished to 0.13 and 0.09 when first grade patterning scores were used as a predictor. Many control variables were entered into the regressions, but such relations cannot safely be considered to indicate causality.

\subsubsection{The Effect of Instruction on Alternating Patterns}

In several cases, children have been given one or two lessons on alternating patterns. There is some very recent empirical evidence indicating that some forms of such brief instruction are better than others. Fyfe, McNeil, and Rittle-Johnson, (2015) found that using abstract terms like "abab" is more helpful to children than concrete terms like "big little big little", and Rittle-Johnson, Saylor, and Swygert (2008) reported that instruction was most helpful if the children explained their reasoning to another person. In two experiments (Rittle-Johnson et al., 2013; Miller et al., 2015), brief instruction had only small effects on the children's performances. There was a significant effect on abstracting the pattern unit when Rittle-Johnson, Fyfe et al. (2015) offered two days of instruction, but not on duplicating or extending patterns. It did not matter whether the instruction was supplied by researchers, or when the children were prompted to develop their own explanations, or a combined approach was used. This suggests that exactly how children should be taught is still to be determined, and may well depend on the children's age and cognitive development. None of these studies of brief instruction of preschoolers have measured any form of academic achievement.

Two studies have involved more extensive instruction. Papic, Mulligan, and Mitchelmore (2011) gave preschoolers 14 sessions of instruction on alternating patterns in more complex configurations than those usually taught, and also added instruction on spatial structure tasks. Twenty-seven children from one Australian preschool served as the experimental group; 26 from another constituted a control group. The children, ranging in age from 41 to 60 months, had 18 30-minute instructional sessions, one per week. There were 12 sessions of instruction on three-color alternations, and two sessions on alternations in a "hopscotch" configuration. In hopscotch configurations blocks of three different colors were used. An example would be a horizontal row of pink, blue, and pink blocks, then two yellow blocks intersecting the row vertically so as to form a $\mathrm{T}$, 
then a horizontal row of pink, blue, and pink blocks, two yellow blocks to form a $\mathrm{T}$, etc. There were also four sessions of instruction on "spatial structure" tasks, wherein the children were to indicate how many dots were enclosed in figures of varying shapes and to copy arrays of dots, triangles made from dots, and configurations made from square blocks.

At the outset of the experiment the children from the school where the intervention was conducted made lower patterning scores than those from the control preschool and made roughly equivalent scores on spatial tasks. At the end of the intervention, they made higher scores on both. They also made higher scores on selected tasks from the Schedule of Early Number Assessment, a test widely used in Australia. However, Papic et al. (2011: 250) reported that "No statistical tests were applied because the two samples were not randomly selected".

There have been many other studies of preschool or school instructional curricula in which instruction on alternating patterns plays some part, but in those the effect of the patterning instruction per se cannot be determined. An exhaustive search has uncovered only one direct test of the effect of extensive instruction on alternating patterns alone. That is Herman's (1973) dissertation, which was never published as a journal article. In her introduction, she advanced the expectation that patterning instruction would foster not only improvement in understanding patterns, but also improvement in classifying, ordering, and conservation, leading to improvement in mathematics. She subsequently administered 24 lessons on alternating patterns to African-American and Spanish-speaking kindergartners from an inner city school. Her statistical analysis was restricted to scores on the Metropolitan Readiness Test (MRT) test of mathematics achievement). The MRT showed a significant difference between the children taught patterning and "control" children from a school in the same neighborhood. Herman also presented scores on a self-constructed 24-item patterning test. At the end of the year, the children who received the patterning instruction scored better on the patterning test, averaging 16.07 items answered correctly as opposed to 11.91 for the control children. Herman did not offer a statistical analysis of this difference, but it would be statistically significant, $t(102)=1.87, p<$ 0.05 , if a one-tailed test were performed. The most important problem with drawing causal inferences from this research is obvious. Children were not randomly assigned to experimental and control groups; they were in fact from different schools. This dissertation appears to have had no effect on the practice of teaching children alternating patterns.

\section{Complex Patterns}

\subsection{Effects of Pattern Characteristics}

There are an almost infinite number of complex pattern types and characteristics. Understanding of pattern which differs in various ways might develop at different rates, and influence children's performances in mathematics or reading in different ways. Again, the research is fragmented. Early studies 
(Gadzichowski, 2012a; 2012b) indicated that the orientation, dimension (letters, numbers, colors, shapes, or objects), type of pattern (alternating ABBABB, symmetrical, growing, or arbitrary) and the position of a missing item (i.e., first. middle, or last item in the pattern) made no difference in first grader's error rates. Only the number of "skips" between items (e.g., 3, 5, 7, 9, 11 vs. 3, 6, 9, 12, 15) made a difference. However, a later study limited to letter and number patterns, Gadzichowski, O’Brien, and Pasnak (2014) showed that orientation made a small but statistically significant difference for first grade children. The interaction between orientation and the dimension (letters or numbers) in which the patterns were presented were more striking. Errors on letter patterns presented vertically were twice those on letter patterns presented horizontally; conversely errors on number patterns presented horizontally were three times those on number patterns presented vertically. The effects were magnified when the patterns were most difficult (i.e., when the skips between items were greater). This study indicates that researchers may find that there are effects of pattern characteristics on children's understanding of patterns, and that the development of patterning is not likely to be an all-or-none phenomenon. It also seems likely that pattern characteristics may affect whether and how much patterning instruction will improve children's progress in mathematics and/or reading.

\subsection{Longitudinal Study of Complex Patterns}

There is evidence that for 6-year-olds, the emergence of understanding of patterns more complex than alternations is connected to understanding of early mathematical concepts. Pasnak et al. (2016) found that first graders' Fall scores on complex patterns (increasing sequences of numbers) did not correlate with their Fall scores on the W-J Number Concepts scales 18A and 18B. There was a significant correlation between the Fall pattern scores and Spring scores on both scales. Hence, within the limitations of the time-lagged design, it appears that understanding patterns precedes and may lead to an understanding of number concepts. Scale 18A is particularly important in this regard, as it is a widely used measure of mathematics concepts. It is worth noting that a similar relationship was not found between letter patterns (alphabetical sequences of letters) and a standardized test of vocabulary (the Test of Word Reading Ability, or TOWRE). This may indicate that there is a reciprocal relationship between understanding patterns of letters and reading, or that some third variable is involved.

Lee, Ng, Bull, Pe, \& Ho (2011) applied a series of structural equation models to show that understanding number patterns of varying complexity and algebra correlated for Singaporean 10-year-olds. The relation was somewhat stronger when the children were a year older, and remained present when computation skills were controlled statistically. Again, the authors cautioned against interpreting these results as proving a causal relationship. The number sequences used $(42,668,43,668$, ?, 45,668, 46,668 is one of the simplest) are much more complex than the alternations used in early education, and the children were older. The study converges with those of Rittle-Johnson, Hofer et al. (2015) and 
Fyfe, Rittle-Johnson et al. (2015) for 8- and 11-year-old in showing a relationship between patterning in some form and mathematics.

\subsection{Instruction on Complex Patterns}

Forty-five Australian children (mean age 8.5 years) were taught "growing" patterns in a study reported by Warren and Cooper (2008) and also by Warren, Cooper, and Lamb (2006). These were geometric patterns which could be extended according to some rule. An example would be two white squares intersected by one black square, four white squares intersected by three black squares, and six white squares intersected by five black squares. The children were given two one-hour lessons on copying and extending such patterns or filling in a gap in such a pattern. During the second lesson, the children were helped to describe the patterns that belonged in any particular position in an effort to improve their thinking and verbal ability to express their understanding of the patterns. A chi-squared analysis comparing pretest and posttest scores indicated that the children had gained a better understanding of the patterns. The researchers interpreted their results as evidence that such young children were capable of thinking about and expressing the relationship between data sets abstractly.

Within the last ten years, four studies have been conducted in which children were taught alternating patterns in conjunction with more complicated patterns. Hendricks, Trueblood, and Pasnak (2006) randomly divided first graders into two groups. The members of the one group were divided into trios; each trio was taught 400 patterns in 15-minute sessions for four months. The instruction began with alternating patterns and continued with a plethora of increasingly more complicated patterns. These included graphic patterns generated by a laptop computer, letter and number matrices in increasing and decreasing orders, arbitrarily generated patterns made of stickers and small objects presented in many formats, causal and temporal sequences depicted via cartoons, and patterns of beads in six, seven, or eight colors. The children in the other group also were divided into trios and received instruction yoked to that of the children taught patterning, on subject matter recommended by their teachers as especially beneficial to them. A MANCOVA (IQ scores were the covariate) showed that the performance of the children taught patterning was superior to that of the control children on the mathematics and written language scales of the Diagnostic Achievement Battery-2. This aligns with the predictions of Sarama and Clements (2004), and Fox (2005), that instruction on patterns would result in general improvement in school performance, (although the former referred to growing patterns and Fox was discussing alternating patterns). Because the children were randomly assigned to groups, and because the instruction of the control children was designed to improve their academic performance, the experiment by Hendricks et al. (2006) was the best evidence at the time that teaching children patterns had a positive effect on their school work. It is noteworthy, however, that most of the patterns were much more complex than the alternations commonly taught in school settings. 
More recently, Kidd (2013) randomly assigned first graders to one experimental and three control groups. The children in each group received $15 \mathrm{mi}$ nutes of instruction thrice weekly for five months. The three control groups received reading, mathematics, or social studies instruction, respectively. The experimental group received instruction on complex patterns modeled on that offered by Hendricks et al. (2006); however, the instructional materials were simplified. The children were taught alternating, random, rotating, or symmetrical patterns made of letters, numbers, shapes, or colors using whiteboards, note cards, and slides presented via computers. All children were tested at the end of the school year on selected scales from the W-J. These were scales 1, 2, or 9, which measure components of reading, scale 10, a measure of mathematics achievement, scale 18A, a measure of mathematics concepts, and scale 18B, which has sequences of numbers governed by increasingly complex rules. There were no significant differences between any children on reading measures. However, the patterning children scored significantly higher than any others on scale 18A. The children taught patterning or mathematics outscored the children taught social studies on scale 18B. This pattern of results indicates that the control mathematics instruction was effective, and that the instruction on complex patterns was even more effective in helping the children to develop early concepts of mathematics. However, these differences in understanding mathematics concepts were not reflected in mathematics achievement, and no form of instruction was more effective than any other in the terms of the aspects of reading measured by W-J scales 1, 2 or 9. Thus, the results of Kidd et al. (2013) only partially corroborate the results of Hendricks et al. (2006). The discrepancy may reflect either differences in the patterning or control instruction, or in the measures employed.

Kidd et al. (2014) essentially replicated Kidd et al. (2013) but employed different tests. The children taught complex patterns subsequently made significantly higher scores than control children the Test of Early Reading Ability-3 (TERA), the Gray Oral Reading Test-4 (GORT), and the TOWRE. They also scored significantly higher than control children on many KEYmath achievement scales and were significantly better than any control group on both $\mathrm{W}-\mathrm{J}$ scales $18 \mathrm{~A}$ and 18B. In terms of grade equivalents (i.e., the average scores on these tests made by American school children) the children taught complex patterns were two to eight months ahead of the control children given matched (yoked) instruction on mathematics or reading or social studies. Such differences, representing the effects of two to eight months of average classroom instruction, are quite important to educators.

Finally Pasnak et al. (2015) replicated the study of Kidd et al. (2014) and partially replicated the results. The children taught either complex patterns or reading outscored the other control children on the TERA and TOWRE reading tests, but not on the GORT. The children taught patterns were significantly better than any group on the W-J scale $18 \mathrm{~A}$ and $18 \mathrm{~B}$, and on the KEYmath algebra scale, and also made consistently higher scores on the other KEYmath scales, al- 
though only a few of the latter differences were significant. Taken together, these three studies provide the most conclusive evidence to date that teaching children complex patterns produces advances in mathematics and reading, as measured by some (but not all) standardized tests.

\section{The Development of Children's Understanding of Patterns}

Preschoolers have often proven capable of duplicating and extending alternating patterns (Clements et al., 2008; Starkey, Klein \& Wakely, 2004) They may recognize and even name new patterns which follow the same rule (Baroody, 1993), indicating that they recognize that the essential nature of the pattern is that it is composed of repeating units. This is equivalent to naming a variable, which is evidence of prealgebraic thought (Clements \& Sarama, 2007).

Some researchers have explored children's ability to identify the repeating unit of an alternating pattern (Clements \& Sarama, 2011; Miller et al., 2015; Papic et al., 2011; Rittle-Johnson et al., 2013). Papic et al. (2011) studied children from two private Australian preschools which enrolled pupils who were competent in English (but $80 \%$ came from non-English-speaking backgrounds). The children gave $34 \%-47 \%$ correct responses on tasks with blocks placed in towers, but were $74 \%-81 \%$ correct when the children were asked to make a the outline of a rectangle with 12 units alternating in an ABAB pattern. However, only $11 \%-19 \%$ were correct in identifying the repeating unit of alternating number sequences like 12121212.

An extensive four-level model of preschoolers' understanding of alternating patterns was provided by Rittle-Johnson et al. (2013). There were large individual differences between these preschoolers. Some could only duplicate a pattern (level 1), others could both duplicate and extend patterns (level 2). Some children could not only duplicate and extend alternating patterns, but also identify the unit of repetition (e.g., $\mathrm{AB}$ or $\mathrm{AABB}$ ) and use it in constructing patterns with new materials (level 3). The most advanced children were able to replicate that unit with the smallest possible number of items (level 4). Such a performance required identifying the pattern rule. Most of the children's explanations of correct solutions were accurate, and became more sophisticated after hearing an adult's explanation in connection with examples and accurate labeling. Rittle-Johnson, Fyfe et al. (2015) followed up these children and found that the preschoolers were nearly perfect on duplicating patterns at the end of their preschool year. At that time most could extend patterns, and the children's ability to abstract patterns (i.e. duplicating a pattern with items differing from the original) had generally doubled. However, there was no significant difference in understanding the unit of replication (replicating that unit with the smallest number of items possible). Miller et al. (2015) also found that for most patterns duplication was easiest, extending a pattern or using different items to represent a pattern came next, and specifying the unit that repeated in the pattern was most difficult. 
Clements and Sarama (2011), testing children enrolled in Head Start, found that $28 \%$ - $48 \%$ of the children could copy an alternating pattern, but only $7 \%-26 \%$ could extend one. A second study showed significantly better performances from Head Start children who were not as economically disadvantaged as those who received free or reduced lunches. Percentages of children who completed or extended patterns successfully were not given for this second study, but the central finding is similar to a result reported by Rittle-Johnson, Fyfe et al. (2015). Disadvantaged children tend to do everything later than children with economic advantages, a finding reported also by Pasnak, Hansbarger, Dodson, Hart, and Blaha (1996), who worked with kindergartners on different cognitive constructs. Trying to pin down the age at which children can identify the unit of repeat or any other characteristic of patterns, or profit from interventions, may be difficult or impossible. The results are very likely to differ for children from different social classes, e. g. those attending subsidized preschools and those attending university preschools for children of faculty and staff.

\section{Cognitive Mechanisms That Support Understanding Patterns}

\subsection{Analogical Reasoning}

The first empirical study that may have identified a cognitive mechanism by which understanding patterns could affect children's mathematics concepts was that of White, Alexander, and Daugherty (1998). Working with preschoolers, this team of educators focused on the relationship between analogical reasoning and the logical-mathematics section of the Georgia Kindergarten Assessment Program (GKAP). This test consists of extending alternating patterns, sorting, making comparisons, recognizing numbers, and counting. The correlation between analogical reasoning and extending patterns was 0.56. About a third (35\%) of the variance in the children's analogical reasoning scores was explained by their GKAP mathematics achievement scores. Nearly all of this relationship was due to the patterning measure. The contributions of sorting, making comparisons of quantity and length, number recognition and counting were negligible. The implication is that analogical reasoning and extending alternating patterns are directly and strongly related. Hence, it is possible that developing an understanding of patterns might improve analogical reasoning, or vice versa. However, the direction of the relationship cannot be determined.

This experiment may be also be compromised by a perceptual similarity between the items used to test analogical reasoning and patterning. Both measures used geometric figures of different colors-circles, squares, triangles, etc. Number recognition is quite different perceptually, the objects counted were three-dimensional, and it is not clear what kinds of things were used in the comparison tasks. This issue does not affect the finding that analogical reasoning and patterning were correlated, but does leave open the possibility that the other measures might also have correlated with analogical reasoning if measures were all perceptually fair. Researchers could devise geometric figures to be used in the 
counting and comparison tasks.

\subsection{Components of Intelligence}

The planning component of Luria's theory, in the case of the Wechsler Intelligence Scale for Children-R, and fluid intelligence, a broad ability $(G f)$ central to the Cattell-Horn-Carroll ( $\mathrm{CHC}$ ) theory, in the case of the Kauffman-ABC and Kauffman-ABC-II, have been nominated as cognitive abilities measured by sequences of pictures used to measure intelligence. The problem is that it is not clear whether these scales actually measure what they are supposed to measure (Allen, Lincoln, \& Kaufman, 1991). The same could be said for the Pattern Reasoning scale, patterns of geometric figures, used in the Kaufmann measures. This scale is clearly one form of patterning, with patterns more advanced than the simple alternations taught in classrooms. It is said to measure fluid reasoning, i.e. the application of both deduction and induction (Kaufman, Lichtenberger, Fletcher-Janzen, \& Kaufman, 2005). Identifying a pattern rule via induction and applying it via deduction to a new pattern which could be solved by the same rule could be the central mechanisms involved in patterning. Pasnak et al. (2015) suggested that in addition to $G f$, two other CHC components, $G q$ (quantitative reasoning) and Grw (a component of reading ability) are likely to be involved in understanding complex patterns, given the impact of instruction on such patterns on early mathematics and reading. If this suggestion is correct, the mechanisms involved would be three components of the $\mathrm{CHC}$, currently the most widely accepted theory of intelligence.

\subsection{Executive Function}

Executive functions (EF) are aspects of thinking known to be related to reading and mathematics achievement (Cartwright, 2012; de Beni \& Palladino, 2000; van der Sluis, de Jong, \& van der Leij, 2007). The three major executive functions are working memory, inhibition, and cognitive flexibility. Working memory involves selectively using information available in memory, inhibition refers to quashing automatic responses or impulses which interfere with the task at hand, and cognitive flexibility is the ability to shift between rule or task characteristics (Duan, Wei, Wang, \& Shi, 2010). These EF components are distinct but correlated with each other (Miyake et al., 2000).

Collins and Laski (2015) assessed preschoolers approaches to alternating patterns, and included two measures of EF. One was the WISC IV Digit Recall scale, in which children recall digits forwards and backwards. The backwards scores were combined with the Corsi Blocks test of visual-spatial memory to form a measure of working memory. Collins and Laski also used the Head-Toes-Knees-Shoulders (HTKS) measure of response inhibition (Ponitz et al., 2008). In this test, the children play a game similar to Simple Simon but must do the opposite of what the experimenter says. Both working memory and inhibition, measured in these ways, correlated with performance on the patterning 
tasks; many of the correlations were medium or large. The children's approaches to the patterning tasks shifted from matching appearances to responses based on the relations exhibited by the patterns as the task became more complex (i.e., changed from duplicating or extending a pattern to transfer tasks).

The effects of working memory (Backward Digit Recall) and inhibition-Hughes (1996) version of Luria's Hand Game-on preschoolers understanding of patterns was also investigated by Miller et al. (2015). These researchers also examined the effects of the third EF (cognitive flexibility) - and of the children's relational knowledge. The FIST task (Jacques \& Zelazo, 2001), wherein children match pictures first on one dimension, then in a different dimension (e.g., first color, then size) was used to measure cognitive flexibility. Relational knowledge was measured by a matching to sample task wherein three units of a pattern were presented $(\mathrm{AAB}, \mathrm{ABB}$, or $\mathrm{ABA})$ and then the child was to select from two alternatives a corresponding $\mathrm{AAB}, \mathrm{ABB}$, or $\mathrm{ABA}$ pattern presented in different colors and shapes. Relational knowledge, measured in this way, predicted children's understanding of patterns before they received two lessons on patterns, but not afterwards. Both working memory and cognitive flexibility, but not inhibitory control, predicted patterning performance before the lessons, but only working memory was predicted patterning performance after the patterning lessons. These results indicate that working memory is an especially important factor in preschoolers' ability to solve alternating patterns. However, they do not show the effect of inhibitory control that Collins and Laski (2015) found with a different sample of preschoolers and a different measure of inhibition.

Both sets of results with preschoolers contrast with those of Bock (2015), who assessed the performance of older children (first graders) on more complicated patterns in terms of three measures of EF. The patterns were single rows of letters, numbers, or pictures of objects that in came progressively later or earlier in the alphabet, increased or decreased in numerical value, increased or decreased in size, or were symmetrical. The Day-Night test (Chasiotis, Kiessling, Hofer, \& Campos, 2006) was used to test inhibition. This is a brief test in which a child is instructed to say "night" when shown a picture of a sun, and to say "day" when shown a picture on a moon. Cartwright's Multiple Classification Card Sorting Test (MCCST; Cartwright, 2002) was used to test cognitive flexibility. In this test, children are given cards with pictures of objects that can be sorted by color or by the type of object depicted on the card, or by both, so as to form a $2 \times 2$ matrix. Finally, the WISC III digit span was used to assess memory capacity (when the numbers were to be repeated in the order they had been read to the child) and working memory (when the numbers were to be repeated backwards). Bock (2015) also administered the GORT-4 reading measure. Only the cognitive flexibility measure was related to patterning. This makes some sense, as these children were two years older than those tested by Collins and Laski (2015) or Miller et al. (2015). It appears that at this age the prepotent responses required by the Day-Night test may have required little inhibition. There was also little 
demand on working memory, as the alternative needed to complete the pattern was one of four presented to the child while the pattern remained visible. However, switching back and forth from increasing, decreasing, and symmetrical patterns does demand flexibility in thinking, and this may account for the relationship observed between patterning and the MCSST.

Bock et al. (2015) also studied first graders, using Bock's (2015) patterning test, the TERA, and Cartwright's (2002) measure of cognitive flexibility. Cognitive flexibility was also measured via a novel computerized task. In essence, the children were asked to maneuver from the upper left-hand corner of a checker board to the lower right-hand corner. Moving from one checker board square to another was based on the colors of the squares, or the shapes contained within them, or the colors of those shapes. Only one of these characteristics allowed the child to proceed, and which characteristic it was changed randomly as the child advanced. Although performances on the two cognitive flexibility measures were correlated, patterning correlated only with the MCCST cognitive flexibility measure. Patterning also correlated with the TERA reading measure, echoing the findings of Kidd et al. (2014) and Pasnak et al. (2015). Neither cognitive flexibility measure correlated with the TERA.

Schmerold et al. (2017) also studied EF, patterning, and academic achievement in first graders. The patterns were more variable than those Bock (2015) employed, and included horizontal and vertical rows of clock faces or numbers that either increased or decreased in value, letters that came progressively earlier or later in the alphabet, and shapes that increased or decreased in size, symmetrical patterns of letters, numbers and shapes, and shapes that rotated through a series of positions. Cognitive complexity was measured with the MCCST, working memory with the Backwards Digit Span (Wechsler, 1974), and inhibition with the Stroop Color-Word Test (Stroop, 1935). The TERA was used to measure reading and W-J scales 10 and 18 were used for mathematics. The relations found between patterning and the EF measures resembled those of Miller et al. (2015). Cognitive flexibility and working memory were significantly related to patterning, but inhibition was not. The correlations for patterning, EF, and academic achievement appeared to differ for reading and mathematics. Mathematics skills were significantly correlated with patterning, cognitive flexibility and working memory, but only patterning and working memory were significantly related to reading. Both regression analyses and structural equation modeling showed that while patterning had effects on both reading and mathematics, the relation between cognitive flexibility and mathematics was entirely mediated by patterning. Working memory had independent effects on reading and mathematics, and also effects moderated by patterning. In sum, these findings suggest that cognitive flexibility and working memory are related to patterning and express their effects on reading and mathematics in whole or in part through patterning. These findings also provide further confirmation of the close relationship between patterning and mathematics. 
Lee et al. (2011) incorporated measures of working memory (updating) and fluid intelligence in their structural equation modeling of the relation between Singaporean 10-year-olds and 11-year-olds' understanding of complex numerical sequences and algebra. Working memory was directly related to proficiency with the number sequences, but the effect of these sequences on algebra was independent of working memory. It was also independent of a measure of fluid intelligence, which was constructed from the WISC Block Design task by using the published reliability of the latter to define its error. There is no mention of administering the Block Design in an otherwise detailed procedure section, and it is puzzling that error was not determined from the scores of the Singaporean students. Perhaps a better measure of fluid intelligence would have yielded a different result. The researchers stated that although they found a close relationship between patterning skills and algebra, they were unable to say just what patterning skills underpinned the relationship, and suggested that future work should address this question. They were certainly correct in that. Much more work is also needed to determine whether age differences, pattern differences, presentation differences, task differences, or all of these, are determinants of the relations between understanding patterns and $\mathrm{EF}$.

\section{Summary and Implications}

Children's understanding of patterns has been approached from several different perspectives. One approach has been to study children's understanding of alternating patterns, and the longitudinal relations between understanding of such patterns and later mathematics achievement. Another has been to study the effects of teaching children patterns-alternating, hopscotch, growing, symmetrical and rotating patterns, and patterns of letters, numbers, and clock faces. The available research generally supports the idea that such instruction supports the development of early mathematics, and various aspects of reading. The recent evidence, from experimental instruction (and also time lag research), is that understanding complex patterns has a causal effect on academic achievement.

Just what mechanisms underpin the effects of instruction on patterns to learning and achievement is open to question. One possibility is that instruction in patterning improves fluid intelligence, and possibly other components of intelligence, as defined by the CHC theory. Another is that such instruction improves EF. This alternative is not attractive at present, because at school age inhibition is not related to patterning, and the effects of cognitive flexibility are completely mediated by patterning. Although working memory is often correlated with performance on pattern measures, it is hard to see how instruction on either alternating patterns or more complex patterns could improve working memory. It is more likely that working memory helps children on those patterning tasks that demand it. The weight of the evidence so far is that patterning has a direct, independent effect, at least upon mathematics. Beyond that, little that is definitive can be said. There have been no experiments with children 
randomly assigned to control groups that show instruction on alternating patterns improves academic performance. Only recently have there been any that show such instruction on complex patterns does improve achievement. Exploration of the parameters of patterns has begun with the work of Gadzichowski (2012a; 2012b) and Gadzichowski et al. (2014), and the study of the natural development of children's understanding of alternating patterns has begun with the research of Rittle-Johnson et al. (2013), Rittle-Johnson, Fyfe et al. (2015) and Miller et al. (2015). Investigation of the mechanisms by which in patterning instruction improves achievement is in its infancy. There is much work to be done. Researchers have many opportunities in the years ahead to determine what cognitive mechanisms are involved in alternating patterns and complex patterns, what characteristics of such patterns are important, and what children profit from instruction on what kinds of pattern. Educators can anticipate that in the decade ahead, much progress will be made.

However, there are already implications for policy and instruction. While the effects of extensive instruction of preschoolers and kindergartners on alternating patterns have not yet been decisively demonstrated, longitudinal studies strongly suggest that children's early understanding of such patterns is correlated with later achievement. Further, the experiments that have been done favor the proposition that extended instruction on alternating patterns benefits preschoolers.

In the case of more complex patterns, the case is much stronger. There is one time-lagged (cross-lagged) study which indicates that the relation between understanding such patterns and subsequently understanding mathematics concepts is probably causal. More convincingly, four experiments (Hendricks et al., 2006; Kidd et al., 2013; Kidd et al., 2014; Pasnak et al., 2015) show that instruction on complex patterns improves both reading and mathematics. Hence, the implication for policy is that patterning instruction should probably be emphasized rather than de-empathized. Educators should move in the direction of such patterning instruction, employing it at least for older children now, in its early form, and discovering the most effective types of patterns and instruction to use as classroom experience and research reveal them.

\section{Acknowledgements}

The research reported here was supported by the Institute of Education Sciences, U.S. Department of Education, through Grant 305A170114 to George Mason University. The opinions expressed are those of the authors and do not represent views of the Institute or the U.S. Department of Education.

\section{References}

Allen, M. H., Lincoln, A. J., \& Kaufman, A. S. (1991). Sequential and Simultaneous Processing Abilities of High-Functioning Autistic and Language-Impaired Children. Journal of Autism and Developmental Disorders, 21, 483-502. https://doi.org/10.1007/BF02206872

Baroody, A. J. (1993). Problem Solving, Reasoning, and Communicating (K-8): Helping 
Kids Think Mathematically. New York, NY: Macmillan.

Bock, A. M. (2015). The Cognitive Components of Patterning: The Relation between EXecutive Function and Patterning. Doctoral Dissertation, George Mason University, Fairfax, VA.

Bock, A., Cartwright, K., Gonzalez, C., O’Brien, S., Robinson, M. F., Schmerold, K., Shriver, A., \& Pasnak, R. (2015). The Role of Cognitive Flexibility in Pattern Understanding. Journal of Education and Human Development, 4, 19-25.

Burton, G. M. (1982) Patterning: Powerful Play. School Science and Mathematics, 82, 39-44. https://doi.org/10.1111/j.1949-8594.1982.tb17161.x

Cartwright, K. B. (2002). Cognitive Development and Reading: The Relation of Reading-Specific Multiple Classification Skill to Reading Comprehension in Elementary School Children. Journal of Educational Psychology, 94, 56-63.

https://doi.org/10.1037/0022-0663.94.1.56

Cartwright, K. B. (2012). Insights from Cognitive Neuroscience: The Importance of Executive Function for Early Reading Development and Education. Early Education and Development, 23, 24-36. https://doi.org/10.1080/10409289.2011.615025

Chasiotis, A., Kiessling, F., Hofer, J., \& Campos, D. (2006) Theory of Mind and Inhibitory Control in Three Cultures: Conflict Inhibition Predicts False Belief Understanding in Germany, Costa Rica, and Cameroon. International Journal of Behavioral Development, 30, 249-260. https://doi.org/10.1177/0165025406066759

Clements, D. H., \& Samara, J. (2007). Early Childhood Mathematics Learning. In F. K. Lester Jr. (Ed.), Second Handbook on Mathematics Teaching and Learning (pp. 461-555). Charlotte, NC: Information Age.

Clements, D. H., \& Sarama, J. (2011). Mathematics Knowledge of Young Children Entering Preschoolers in the U. S. Far Eastern Journal of Mathematics Education, 6, 41-63. http://pphmj.com/journals/fjme/htm

Clements, D. H., Sarama, J., \& Liu, X. H. (2008). Development of a Measure of Early Mathematics Achievement Using the Rasch Model: The Research-Based Early Math Assessment. Educational Psychology, 28, 457-482. https://doi.org/10.1080/01443410701777272

Collins, M. A., \& Laski, E. V. (2015). Preschoolers Strategies for Solving Visual Pattern Tasks. Early Childhood Research Quarterly, 32, 204-214. https://doi.org/10.1016/j.ecresq.2015.04.004

de Beni, R., \& Palladino, P. (2000). Intrusion Errors in Working Memory Tasks: Are They Related to Reading Comprehension Ability? Learning and Individual Differences, 12, 131-143.

Duan, X., Wei, S., Wang, G., \& Shi, J. (2010). The Relationship between Executive Functions and Intelligence on 11- to 12-Year-Old Children. Psychological Test and Assessment Modeling, 52, 419-431.

Economopolous, K. (1998). What Comes Next? The Mathematics of Patterning in Kindergarten. Teaching Children Mathematics, 5, 230-233. http://www.jstor/stable/41197171?seq=1\#page_scan_tab_contents

Fox, J. (2005). Child-Initiated Mathematical Patterning in the Pre-Compulsory Years (p. 313). International Group for the Psychology of Mathematics Education. http://eprints.que.edu.au.archive/0004247

Fyfe, E. R., McNeil, N. M., \& Rittle-Johnson, B. (2015). Easy as ABCABC: Abstract Language Facilitates Performance on a Concrete Patterning Task. Child Development. https://doi.org/10.1111/cdev.12331 
Fyfe, E. R., Rittle-Johnson, B., Hofer, K., \& Farren, D. C. (2015). Pattern Knowledge, But Not Shape Knowledge, Predicts 5 th Grade Math Outcomes. Columbus, OH: Poster Session Presented at the Biennial Meeting of the Cognitive Development Society.

Gadzichowski, K. M. (2012a). Examining Patterning Abilities in First Grade Children: A Comparison of Dimension, Orientation, Number of Items Skipped and Position of the Missing Item. Psychology, 3, 1171-1182. https://doi.org/10.4236/psych.2012.312A174

Gadzichowski, K. M. (2012b). Patterning Abilities of First Grade Students: Effects of Dimension and Type. Creative Education, 3, 632-635. https://doi.org/10.4236/ce.2012.35092

Gadzichowski, K. M., O’Brien, S. E., \& Pasnak, R. (2014). Orientation of Patterns of Letters or Numbers. Journal of Education and Human Development, 3, 59-66.

Hendricks, C., Trueblood, L., \& Pasnak, R. (2006). Effects of Teaching Patterning to First Graders. Journal of Research on Childhood Education, 21, 77-87. https://doi.org/10.1080/02568540609594580

Herman, M. L. (1973). Patterning before Mathematics in Kindergarten. Dissertation Abstracts International, 33, 4060.

Hughes, C. (1996). Control of Action and Thought: Normal Development and Dysfunction in Autism: A Research Note. Journal of Child Psychology and Psychiatry, 37, 229-236. https://doi.org/10.1111/j.1469-7610.1996.tb01396.x

Jacques, S., \& Zelazo, P. D. (2001). The Flexible Item Selection Task (FIST): A Measure of Executive Function in Preschoolers. Developmental Neuropsychology, 20, 573-591. http://www.tandfonline.com/doi/abs/10.1207/S15326942DN2003_2 https://doi.org/10.1207/S15326942DN2003_2

Jarboe, T., \& Sadler, S. (2003). It's as Easy as 1,2,3: Patterns and Activities for a Creative, Balanced Mathematics Program. Peterborough, NJ: Crystal Springs Books.

Kaufman, A. S., Lichtenberger, E. O., Fletcher-Janzen, E., \& Kaufman, N. L. (2005). Essentials of KABC-II Assessment. Hoboken, NJ: John Wiley \& Sons, Inc.

Kidd, J. K., Carlson, A. G., Gadzichowski, K. M., Boyer, C. E., Gallington, D. A., \& Pasnak, R. (2013). Effects of Patterning Instruction on the Academic Achievement of First Grade Children. Journal of Research in Childhood Education, 27, 224-238. https://doi.org/10.1080/02568543.2013.766664

Kidd, J. K.,, Pasnak, R., Gadzichowski, K. M., Gallington, D. A., McKnight, P. E., Boyer, C. E., \& Carlson, A. (2014). Instructing First-Grade Children on Patterning Improves Reading and Mathematics. Early Education and Development, 25, 134-151. https://doi.org/10.1080/10409289.2013.794448

Lee, K., Ng, S., Bull, R., Pe, M., \& Ho, R. (2011). Are Patterns Important? An Investigation of the Relationships between Proficiencies in Patterns, Computation, Executive Functioning, and Algebraic Word Problems. Journal of Educational Psychology, 103, 269-281. https://doi.org/10.1037/a0023068

Miller, M. R., Rittle-Johnson, B., Loehr, A. M., \& Fyfe, E. R. (2015). The Influence of Relational Knowledge and Executive Function on Preschoolers' Repeating Pattern Knowledge. Journal of Cognition and Development, 17, 85-104. https://doi.org/10.1080/15248372.2015.1023307

Miyake, A., Friedman, N. P., Emerson, M. J., Witzki, A. H., Howerter, A., \& Wager, T. (2000). The Unity and Diversity of Executive Functions and Their Contributions to Complete "Frontal Lobe" Tasks: A Latent Variable Analysis. Cognitive Psychology, 41, 49-100. https://doi.org/10.1006/cogp.1999.0734

Mulligan, J., Mitchelmore, M., Kemp, C., Marston, J., \& Highfield, K. (2008). Encourag- 
ing Mathematical Thinking through Pattern and Structure: An Intervention in the First Year of Schooling. Macquarie University Research Online.

http://www.aamt.edu.au/

National Association for the Education of Young Children/National Council of Teachers of Mathematics Education (2002/2010). Early Childhood Mathematics: Promoting Good Beginnings. Washington DC: NYAEC.

http://www.state.nj.us/education/ece/pd/math/naeyc_nctm.pdf

National Council of Teachers of Mathematics (2015). Principles and Standards for School Mathematics. Reston, VA: NCTM.

Papic, M. M., Mulligan, J. T., \& Mitchelmore, M. C. (2011). Assessing the Development of Preschoolers' Mathematical Thinking. Journal for Research for Mathematics Education, 42, 237-268. https://doi.org/10.5951/jresematheduc.42.3.0237

Pasnak, R., Hansbarger, A., Dodson, S. L., Hart, J. B., \& Blaha, J. (1996). Differential Results of Instruction at the Preoperational-Concrete Operational Transition. Psychology in the Schools, 33, 70-83.

Pasnak, R., Kidd, J. K., Gadzichowski, K. M., Gallington, D. A., Schmerold, K. L., \& West, H. M. (2015). Abstracting Sequences: Reasoning That Is a Key to Academic Achievement. Journal of Genetic Psychology, 176, 171-193. https://doi.org/10.1080/00221325.2015.1024198

Pasnak, R., Schmerold, K. L., Robinson, M. F., Gadzichowski, K. M., Bock, A. M., O’Brien, S. E., Kidd, J. K., \& Gallington, D. A. (2016). Understanding Number Sequences Leads to Understanding Number Concepts. Journal of Educational Research, 109, 640-646. https://doi.org/10.1080/00220671.2015.1020911

Ponitz, C. E. C., McClellen, M. M., Jewkes, A. M., Connor, C. M., Farris, C. L., \& Morrison, F. J. (2008). Touch Your Toes! Developing a Direct Measure of Behavioral Regulation in Early Childhood. Early Childhood Research Quarterly, 23, 141-158.

https://doi.org/10.1016/j.ecresq.2007.01.004

Rittle-Johnson, B., Fyfe, E. R., McLean, L. E., \& McEldoon, K. L. (2013) Emerging Understanding of Patterning in 4-Year-Olds. Journal of Cognition and Development, 14, 376-396. https://doi.org/10.1080/15248372.2012.689897

Rittle-Johnson, B., Fyfe, M. R., Loehr, A. M., \& Miller, M. R. (2015). Beyond Numeracy in Preschool: Adding Patterning to the Equation. Early Childhood Research Quarterly, 31, 101-112. https://doi.org/10.1016/j.ecresq.2015.01.005

Rittle-Johnson, B., Hofer, K., Fyfe, M. R., \& Farren, D. C. (2015). It's a Pattern! The Importance of Early Pattern Knowledge for Middle School Mathematics Achievement. Philadelphia, PA: Poster Session Presented at the Biennial Conference of the Society for Research in Child Development.

Rittle-Johnson, B., Saylor, M., \& Swygert, K. (2008). Learning from Explaining: Does It Matter if Mom Is Listening? Journal of Experimental Child Psychology, 100, 215-224. https://doi.org/10.1016/j.jecp.2007.10.002

Sarama, J., \& Clements, D. H. (2004). Building Blocks for Early Childhood Mathematics. Early Childhood Research Quarterly, 19, 181-189.

https://doi.org/10.1016/j.ecresq.2004.01.014

Schmerold, K., Bock, A., Peterson, M., Leaf, B., Vennergrund, K., \& Pasnak, R. (2017). The Relations between Patterning, Executive Function, and Mathematics. The Journal of Psychology, 151, 1-23.

Starkey, P., Klein, A., \& Wakely, A. (2004). Enhancing Young Children's Mathematical Knowledge through a Pre-Kindergarten Mathematics Intervention. Early Childhood 
Research Quarterly, 19, 99-120. https://doi.org/10.1016/j.ecresq.2004.01.002

Stroop, J. R. (1935). Studies of Interference in Serial Verbal Reactions. Journal of Experimental Psychology, 18, 643-662. https://doi.org/10.1037/h0054651 https://www.scribd.com/document/49683284/Stroop-Stroop-1935

Van der Sluis, S., de Jong, P. F., \& van der Leij, A. (2007). Executive Functioning in Children, and Its Relations with Reasoning, Reading, and Arithmetic. Intelligence, 35, 427-449. https://doi.org/10.1016/j.intell.2006.09.001

Warren, E. A., \& Cooper, T. J. (2008). Generalising the Pattern Rule for Visual Growth Patterns: Actions That Support 8 Year Olds' Thinking. Educational Studies in Mathematics, 67, 171-185. https://doi.org/10.1007/s10649-007-9092-2

Warren, E. A., Cooper, T. J., \& Lamb, J. T. (2006). Investigating Functional Thinking Is the Elementary Classroom: Foundations of Early Algebraic Reasoning. Journal of Mathematics Behavior, 25, 208-223. https://doi.org/10.1016/j.jmathb.2006.09.006

Wechsler, D. (1974). Wechsler Intelligence Scale for Children (Revised ed.). San Antonio, TX: The Psychological Corporation.

White, S., Alexander, P. A., \& Daugherty, M. (1998). The Relationship between Young Children's Analogical Reasoning and Mathematical Learning. Mathematical Cognition, 4, 103-123. https://doi.org/10.1080/135467998387352 